\title{
CONVERGENCE THEOREMS FOR UNIFORMLY QUASI-LIPSCHITZIAN MAPPINGS
}

\author{
HAIYUN ZHOU, JUNG IM KANG, SHIN MIN KANG, and YEOL JE CHO
}

Received 15 September 2003

\begin{abstract}
We prove some convergence theorems of the modified Ishikawa iterative sequence with errors for uniformly quasi-Lipschitzian mappings in metric spaces. Our results generalize and improve the corresponding results of Petryshyn and Williamson, Ghosh and Debnath, Liu, and many others.
\end{abstract}

2000 Mathematics Subject Classification: 54H25, 47H10.

Let $C$ be a nonempty subset of a normed linear space $(X,\|\cdot\|)$ and $T: C \rightarrow C$ a given mapping. Let $F(T)$ denote the set of fixed points of $T$.

DEFINITION 1. (1) The mapping $T$ is said to be nonexpansive if

$$
\|T x-T y\| \leq\|x-y\|, \quad x, y \in C \text {. }
$$

(2) The mapping $T$ is said to be quasi-nonexpansive if $F(T) \neq \varnothing$ and

$$
\|T x-p\| \leq\|x-p\|, \quad x \in C, p \in F(T) .
$$

(3) The mapping $T$ is said to be asymptotically nonexpansive if there exists a sequence $\left\{k_{n}\right\}$ of nonnegative real numbers with $k_{n} \rightarrow 0$ as $n \rightarrow \infty$ such that

$$
\left\|T^{n} x-T^{n} y\right\| \leq\left(1+k_{n}\right)\|x-y\|, \quad x, y \in C, n \geq 1 .
$$

(4) The mapping $T$ is said to be asymptotically quasi-nonexpansive if $F(T) \neq \varnothing$ and there exists a sequence $\left\{k_{n}\right\}$ of nonnegative real numbers with $k_{n} \rightarrow 0$ as $n \rightarrow \infty$ such that

$$
\left\|T^{n} x-p\right\| \leq\left(1+k_{n}\right)\|x-p\|, \quad x \in C, p \in F(T) .
$$

(5) The mapping $T$ is said to be of asymptotically nonexpansive type if, for any $x \in C$,

$$
\limsup _{n \rightarrow \infty}\left(\sup \left\{\left\|T^{n} x-T^{n} y\right\|-\|x-y\|: y \in C\right\}\right) \leq 0 .
$$

(6) The mapping $T$ is said to be of asymptotically quasi-nonexpansive type if $F(T) \neq \varnothing$ and

$$
\limsup _{n \rightarrow \infty}\left(\sup \left\{\left\|T^{n} x-p\right\|-\|x-p\|: p \in F(T)\right\}\right) \leq 0, \quad x \in C .
$$


(7) The mapping $T$ is said to be demicontractive if $F(T) \neq \varnothing$ and there exists some constant $k \in[0,1)$ such that

$$
\|T x-p\|^{2} \leq\|x-p\|^{2}+k\|x-T x\|^{2}, \quad x \in C, p \in F(T) .
$$

(8) The mapping $T$ is said to be hemicontractive if $F(T) \neq \varnothing$ and

$$
\|T x-p\|^{2} \leq\|x-p\|^{2}+\|x-T x\|^{2}, \quad x \in C, p \in F(T) .
$$

(9) The mapping $T$ is called asymptotically demicontractive if $F(T) \neq \varnothing$ and there exist a sequence $\left\{k_{n}\right\}$ with $k_{n} \geq 1$ and $k_{n} \rightarrow 1$ and a constant $k \in[0,1)$ such that

$$
\|T x-p\|^{2} \leq k_{n}^{2}\|x-p\|^{2}+k\|x-T x\|^{2}, \quad x \in C, p \in F(T) .
$$

(10) The mapping $T$ is said to be asymptotically hemicontractive if $F(T) \neq \varnothing$ and there exists a sequence $\left\{k_{n}\right\}$ with $k_{n} \geq 1$ and $k_{n} \rightarrow 1$ such that

$$
\|T x-p\|^{2} \leq k_{n}^{2}\|x-p\|^{2}+\|x-T x\|^{2}, \quad x \in C, p \in F(T) .
$$

(11) The mapping $T$ is said to be uniformly Lipschitzian if there exists a positive constant $L$ such that

$$
\left\|T^{n} x-T^{n} y\right\| \leq L\|x-y\|, \quad x, y \in C, n \geq 1 .
$$

(12) The mapping $T$ is said to be uniformly quasi-Lipschitzian if $F(T) \neq \varnothing$ and there exists a positive constant $L$ such that

$$
\left\|T^{n} x-p\right\| \leq L\|x-p\|, \quad x \in C, p \in F(T), n \geq 1 .
$$

These classes of mappings mentioned above have been studied extensively by various authors (see $[1,2,3,6,7,8,9,10,11,12,13,14,16,17,19,20,21,23,24,25,26$, 27]) and several important fixed point theorems have been established successfully for the classes of nonexpansive mappings and asymptotically nonexpansive mappings as well as the mappings of asymptotically nonexpansive type in nearly uniformly convex Banach spaces (see $[7,10,25]$ ). Also, various iterative schemes in connection with these classes of mappings have been introduced and used to approximate fixed points of these classes of mappings (see [1, 2, 3, 4, 13, 19, 20, 26]).

REMARK 2. (1) It is clear that the nonexpansive mappings with the nonempty fixed point set $F(T)$ are quasi-nonexpansive.

(2) The linear quasi-nonexpansive mappings are nonexpansive, but it is easily seen that there exist nonlinear continuous quasi-nonexpansive mappings which are not nonexpansive; for example, define $T x=(x / 2) \sin (1 / x)$ for all $x \neq 0$ and $T 0=0$ in $\mathbb{R}$.

(3) It is obvious that if $T$ is nonexpansive, then it is asymptotically nonexpansive with the constant sequence $\{1\}$.

(4) If $T$ is asymptotically nonexpansive, then it is uniformly Lipschitzian with $L=$ $\sup \left\{k_{n}: n \geq 1\right\}$ and asymptotically pseudocontractive. However, the converses of these claims are not true. 
(5) It is easily seen that, if $C$ is a bounded subset of $X$ and $T: C \rightarrow C$ is asymptotically nonexpansive, then it must be of asymptotically nonexpansive type. However, the converse is not true.

(6) If $T$ is asymptotically nonexpansive with $F(T) \neq \varnothing$, then it is uniformly quasiLipschitzian. For more comparisons of these mappings, readers may refer to Chang et al. [1] and the references therein.

REMARK 3. We note here that the fixed point set $F(T)$ of a uniformly quasi-Lipschitzian mapping $T$ is a closed subset of $D$ provided that $D$ is closed. To see this, assume that $\left\{p_{n}\right\} \subset F(T)$ with $p_{n} \rightarrow p$ as $n \rightarrow \infty$. Then $p \in D$ since $D$ is closed. By the definition of $T$, we have

$$
\left\|T p-p_{n}\right\| \leq L\left\|p-p_{n}\right\|
$$

which implies that $T p=p$.

In 1991, Schu [19, 20] introduced the following iterative schemes: let $X$ be a normed linear space, let $C$ be a nonempty convex subset of $X$, and let $T: C \rightarrow C$ be a given mapping. Then, for arbitrary $x_{1} \in C$, the modified Ishikawa iterative scheme $\left\{x_{n}\right\}$ is defined by

$$
\begin{aligned}
y_{n} & =\left(1-\beta_{n}\right) x_{n}+\beta_{n} T^{n} x_{n}, \quad n \geq 1, \\
x_{n+1} & =\left(1-\alpha_{n}\right) x_{n}+\alpha_{n} T^{n} y_{n}, \quad n \geq 1,
\end{aligned}
$$

where $\left\{\alpha_{n}\right\}$ and $\left\{\beta_{n}\right\}$ are some suitable sequences in $[0,1]$. With $X, C,\left\{\alpha_{n}\right\}$, and $x_{1}$ as above, the modified Mann iterative scheme $\left\{x_{n}\right\}$ is defined by

$$
\begin{gathered}
x_{1} \in C, \\
x_{n+1}=\left(1-\alpha_{n}\right) x_{n}+\alpha_{n} T^{n} x_{n}, \quad n \geq 1 .
\end{gathered}
$$

In 1998, Xu [26] introduced the following iterative scheme with errors: let $X$ be a normed linear space, let $C$ be a nonempty convex subset of $X$, and let $T: C \rightarrow C$ be a given mapping. Then, for arbitrary $x_{1} \in C$, the Ishikawa iterative scheme $\left\{x_{n}\right\}$ with errors is defined by

$$
\begin{aligned}
& y_{n}=\bar{a}_{n} x_{n}+\bar{b}_{n} T x_{n}+\bar{c}_{n} v_{n}, \quad n \geq 1, \\
& x_{n+1}=a_{n} x_{n}+b_{n} T y_{n}+c_{n} u_{n}, \quad n \geq 1 \text {, }
\end{aligned}
$$

where $\left\{u_{n}\right\},\left\{v_{n}\right\}$ are bounded sequences in $C$ and $\left\{a_{n}\right\},\left\{b_{n}\right\},\left\{c_{n}\right\},\left\{\bar{a}_{n}\right\},\left\{\bar{b}_{n}\right\},\left\{\bar{c}_{n}\right\}$ are sequences in $[0,1]$ with $a_{n}+b_{n}+c_{n}=\bar{a}_{n}+\bar{b}_{n}+\bar{c}_{n}=1$. With $X, C,\left\{u_{n}\right\},\left\{a_{n}\right\},\left\{b_{n}\right\}$, $\left\{c_{n}\right\}$, and $x_{1}$ as above, the Mann iterative scheme $\left\{x_{n}\right\}$ with errors is defined by

$$
\begin{gathered}
x_{1} \in C, \\
x_{n+1}=a_{n} x_{n}+b_{n} T x_{n}+c_{n} u_{n}, \quad n \geq 1 .
\end{gathered}
$$

Based on the iterative scheme with errors introduced by $\mathrm{Xu}$ [26], the following iterative schemes have been used and studied by several authors (see [1, 2, 13, 16]). 
Let $X$ be a normed linear space, let $C$ be a nonempty convex subset of $X$, and let $T: C \rightarrow C$ be a given mapping. Then, for arbitrary $x_{1} \in C$, the modified Ishikawa iteration scheme $\left\{x_{n}\right\}$ with errors is defined by

$$
\begin{aligned}
& y_{n}=\bar{a}_{n} x_{n}+\bar{b}_{n} T^{n} x_{n}+\bar{c}_{n} v_{n}, \quad n \geq 1, \\
& x_{n+1}=a_{n} x_{n}+b_{n} T^{n} y_{n}+c_{n} u_{n}, \quad n \geq 1 \text {, }
\end{aligned}
$$

where $\left\{u_{n}\right\},\left\{v_{n}\right\}$ are bounded sequences in $C$ and $\left\{a_{n}\right\},\left\{b_{n}\right\},\left\{c_{n}\right\},\left\{\bar{a}_{n}\right\},\left\{\bar{b}_{n}\right\},\left\{\bar{c}_{n}\right\}$ are sequences in $[0,1]$ with $a_{n}+b_{n}+c_{n}=\bar{a}_{n}+\bar{b}_{n}+\bar{c}_{n}=1$. With $X, C,\left\{u_{n}\right\},\left\{a_{n}\right\},\left\{b_{n}\right\}$, $\left\{c_{n}\right\}$, and $x_{1}$ as above, the modified Mann iteration scheme $\left\{x_{n}\right\}$ with errors is defined by

$$
\begin{gathered}
x_{1} \in C, \\
x_{n+1}=a_{n} x_{n}+b_{n} T^{n} x_{n}+c_{n} u_{n}, \quad n \geq 1 .
\end{gathered}
$$

On the other hand, Petryshyn and Williamson [17] in 1973 presented some sufficient and necessary conditions for the Mann iterative sequence to converge to fixed points for quasi-nonexpansive mappings as follows.

THEOREM 4. Let D be a closed subset of a Banach space X, and T map D continuously into $X$ such that

(i) $F(T) \neq \varnothing$,

(ii) the mapping $T$ is quasi-nonexpansive,

(iii) there exists $x_{0} \in D$ such that

$$
x_{n}=T^{n} x_{0} \in D, \quad n \geq 1 .
$$

Then the sequence $\left\{x_{n}\right\}$ converges to a point in $F(T)$ if and only if

$$
\lim _{n \rightarrow \infty} d\left(x_{n}, F(T)\right)=0 .
$$

THEOREM 5. Let D be a closed convex subset of a Banach space $X$, and $T$ a continuous mapping from $D$ into $X$ such that

(i) $F(T) \neq \varnothing$,

(ii) the mapping $T$ is quasi-nonexpansive,

(iii) there exist $x_{0} \in D$ and $\lambda \in(0,1)$ such that

$$
x_{n}=T_{\lambda}^{n} x_{0} \in D, \quad n \geq 1 .
$$

Then the sequence $\left\{x_{n}\right\}$ converges to a point in $F(T)$ if and only if $\lim _{n \rightarrow \infty} d\left(x_{n}, F(T)\right)$ $=0$.

THEOREM 6. Let D be a closed subset of a Banach space X, and T map D continuously into $X$ such that

(i) $F(T) \neq \varnothing$,

(ii) the mapping $T$ is quasi-nonexpansive,

(iii) there exists $x_{0} \in D$ such that

$$
x_{n}=T^{n} x_{0} \in D, \quad n \geq 1,
$$


(iv) the mapping $T$ is asymptotically regular at $x_{0}$, that is,

$$
T^{n} x_{0}-T^{n+1} x_{0} \longrightarrow 0 \text { as } n \rightarrow \infty
$$

(v) if $\left\{y_{n}\right\}$ is a sequence in $D$ for all $n \geq 1$ and $\left\|(I-T) y_{n}\right\| \rightarrow 0$ as $n \rightarrow \infty$, where $I$ is the identity mapping on $D$,

$$
\liminf _{n \rightarrow \infty} d\left(y_{n}, F(T)\right)=0 .
$$

Then the sequence $\left\{x_{n}\right\}$ converges to a point in $F(T)$.

For further details on Theorems 4, 5, and 6, and their examples, refer to Petryshyn and Williamson [17].

In 1996, Zhou and Jia [28] gave some sufficient conditions for the Ishikawa iterative sequence to converge to fixed points for quasi-nonexpansive mappings in a real uniformly convex Banach space. In 1997, Ghosh and Debnath [6] extended Theorems 4,5 , and 6 and proved the sufficient and necessary condition for the Ishikawa iterative sequence to converge to fixed points for quasi-nonexpansive mappings. Recently, Liu $[12,13]$ has extended the above results to the class of asymptotically quasinonexpansive mappings and gave some sufficient and necessary conditions to converge to fixed points for the modified Ishikawa iterative sequence of asymptotically quasinonexpansive mappings.

Let $C$ be a nonempty subset of a normed linear space $X$ and let $T: C \rightarrow C$ be a self-mapping. For any $x_{1} \in C$, define a sequence $\left\{x_{n}\right\}$ in $C$ by

$$
x_{n}=T_{\lambda, \mu}^{n} x_{1}, \quad T_{\lambda, \mu}=(1-\lambda) I+\lambda T T_{\mu},
$$

where $\lambda \in(0,1), \mu \in[0,1)$, and $T_{\mu}=(1-\mu) I+\mu T$.

In [6], Ghosh and Debnath proved the following result.

THEOREM 7. Let $C$ be a nonempty closed convex subset of a Banach space $X$ and let $T: C \rightarrow C$ be a continuous mapping such that

(i) $F(T) \neq \varnothing$,

(ii) $T$ is quasi-nonexpansive, that is, for all $x \in C$ and $p \in F(T)$,

$$
\|T x-p\| \leq\|x-p\| .
$$

Then, for any $x_{1} \in C$, the sequence $\left\{x_{n}\right\}$ with $x_{n}=T_{\lambda, \mu}^{n} x_{1}$ converges to a fixed point of $T$ in $D$ if and only if $\lim _{n \rightarrow \infty} d\left(x_{n}, F(T)\right)=0$.

REMARK 8. We noted that in Theorem 7, the only use of continuity assumption imposed on $T$ is to ensure the closedness of $F(T)$. Note that $F(T)$ is indeed a closed subset of $D$ and we see that the continuity assumption imposed on $T$ is unnecessary.

Very recently, Liu $[12,13]$ extended Theorem 7 as follows.

THEOREM 9. Let $E$ be a nonempty closed convex subset of a Banach space $X$ and let $T: E \rightarrow E$ be an asymptotically quasi-nonexpansive mapping with the nonempty fixed 
point set $F(T)$. Let $\left\{x_{n}\right\}$ be a sequence defined by

$$
\begin{gathered}
x_{1} \in E, \\
y_{n}=\left(1-\beta_{n}\right) x_{n}+\beta_{n} T^{n} x_{n}, \quad n \geq 1, \\
x_{n+1}=\left(1-\alpha_{n}\right) x_{n}+\alpha_{n} T^{n} y_{n}, \quad n \geq 1,
\end{gathered}
$$

where $\left\{\alpha_{n}\right\}$ and $\left\{\beta_{n}\right\}$ are sequences in $[0,1]$ with $\sum_{n=1}^{\infty} k_{n}<\infty$. Then the sequence $\left\{x_{n}\right\}$ converges to a fixed point of $T$ if and only if

$$
\liminf _{n \rightarrow \infty} d\left(x_{n}, F(T)\right)=0 .
$$

THEOREM 10. Let $E$ be a nonempty closed convex subset of a Banach space $X$ and let $T: E \rightarrow E$ be an asymptotically quasi-nonexpansive mapping with the nonempty fixed point set $F(T)$. Let $\left\{x_{n}\right\}$ be a sequence defined by

$$
\begin{gathered}
x_{1} \in E, \\
y_{n}=\bar{a}_{n} x_{n}+\bar{b}_{n} T^{n} x_{n}+\bar{c}_{n} v_{n}, \quad n \geq 1, \\
x_{n+1}=a_{n} x_{n}+b_{n} T^{n} y_{n}+c_{n} u_{n}, \quad n \geq 1,
\end{gathered}
$$

where $\left\{u_{n}\right\},\left\{v_{n}\right\}$ are bounded sequences in $C$ and $\left\{a_{n}\right\},\left\{b_{n}\right\},\left\{c_{n}\right\},\left\{\bar{a}_{n}\right\},\left\{\bar{b}_{n}\right\},\left\{\bar{c}_{n}\right\}$ are sequences in $[0,1]$ with $a_{n}+b_{n}+c_{n}=\bar{a}_{n}+\bar{b}_{n}+\bar{c}_{n}=1, \sum_{n=1}^{\infty} k_{n}<\infty, \sum_{n=1}^{\infty} c_{n}<\infty$, and $\sum_{n=1}^{\infty} \bar{c}_{n}<\infty$. Then the sequence $\left\{x_{n}\right\}$ converges to a fixed point of $T$ if and only if $\liminf _{n \rightarrow \infty} d\left(x_{n}, F(T)\right)=0$.

REMARK 11. We note that the proofs of Ghosh and Debnath [6, Theorem 1], and Liu [12, Theorem 1], [13, Theorem 1] have some common ingredients. This fact enlightens us to explore the possibility to establish more general results.

Let $(X, d)$ be a metric space, let $C$ be a nonempty subset of $X$, and let $T: C \rightarrow C$ be a given mapping with the nonempty fixed point set $F(T)$. Suppose that the iterative scheme $\gamma: x_{n+1}=\gamma\left(T, x_{n}\right)$ for all $n \geq 1$ is well-defined with respect to the chosen iterative parameters. The iterative scheme $\gamma$ or iterative sequence $\left\{x_{n}\right\}$ is said to be of monotone type (see [27]) if there exist sequences $\left\{r_{n}\right\}$ and $\left\{s_{n}\right\}$ of nonnegative real numbers such that $\sum_{n=1}^{\infty} r_{n}<\infty, \sum_{n=1}^{\infty} s_{n}<\infty$, and the following inequality holds:

$$
d\left(x_{n+1}, p\right) \leq\left(1+r_{n}\right) d\left(x_{n}, p\right)+s_{n}, \quad p \in F(T), n \geq 1 \text {. }
$$

REMARK 12. Several known results on the convergence theorems have shown that the iterative schemes of monotone type are rich in examples. In this connection, readers can refer to Chang et al. [1], Chidume [2], Osilike and Igbokwe [16], and the references therein.

Recently, in [27], Zhou et al. proved the following theorem.

THEOREM 13. Let $C$ be a nonempty subset of a complete metric space $(X, d)$ and let $T: C \rightarrow C$ be a mapping with the nonempty closed fixed point set $F(T)$. Suppose that the iterative scheme $\gamma: x_{n+1}=\gamma\left(T, x_{n}\right)$ is of monotone type. Then the sequence $\left\{x_{n}\right\}$ 
converges strongly to some $p \in F(T)$ if and only if

$$
\liminf _{n \rightarrow \infty} d\left(x_{n}, F(T)\right)=0
$$

where $d(x, F(T))=\inf \{d(x, p): p \in F(T)\}$.

Note that

$$
\liminf _{n \rightarrow \infty} d\left(x_{n}, F(T)\right)=0
$$

if and only if there exists a subsequence $\left\{x_{n_{j}}\right\}$ of $\left\{x_{n}\right\}$ such that $\left\{x_{n_{j}}\right\}$ converges to a point $p \in F(T)$.

Thus we have the following theorem.

THEOREM 14. Let $C$ be a nonempty subset of a complete metric space $(X, d)$ and let $T: C \rightarrow C$ be a mapping with the nonempty closed fixed point set $F(T)$. Suppose that the iterative sequence $\left\{x_{n}\right\}$ is of monotone type. Then the sequence $\left\{x_{n}\right\}$ converges strongly to some $p \in F(T)$ if and only if there exists a subsequence $\left\{x_{n_{j}}\right\}$ of $\left\{x_{n}\right\}$ such that $\left\{x_{n_{j}}\right\}$ converges to a point $p \in F(T)$.

REMARK 15. In Banach spaces, Theorems 13 and 14 are also still true. As applications of Theorems 13 and 14, we can deduce Theorems 7, 9, and 10 from Banach spaces to abstract metric spaces.

REMARK 16. If the completeness of $X$ is replaced by the compactness of subset $C$, then the conclusions of Theorems 13 and 14 still hold. In fact, when $C$ is a compact convex subset of $(X, d)$, then $C$ is complete.

From Theorem 13, we have the following corollary.

Corollary 17. Let $X, C, T$, and $\left\{x_{n}\right\}$ be same as in Theorem 13. Suppose, furthermore, that the following conditions hold:

(i) $T$ is asymptotically regular in $x_{0}$, that is,

$$
\liminf _{n \rightarrow \infty} d\left(x_{n}, T x_{n}\right)=0
$$

(ii) $\liminf _{n \rightarrow \infty} d\left(x_{n}, T x_{n}\right)=0$ implies that

$$
\liminf _{n \rightarrow \infty} d\left(x_{n}, F(T)\right)=0 .
$$

Then the sequence $\left\{x_{n}\right\}$ converges strongly to a fixed point of $T$.

Corollary 18. Let $X, C, T$, and $\left\{x_{n}\right\}$ be the same as in Theorem 13. Assume that $T$ is asymptotically regular in $x_{0}$ and satisfies condition (14), that is, there is an increasing function $f: \mathbb{R}^{+} \rightarrow \mathbb{R}^{+}$with $f(0)=0$ and $f(r)>0$ for all $r>0$ such that

$$
d\left(x_{n}, T x_{n}\right) \geq f\left(d\left(x_{n}, F(T)\right)\right)
$$

for all $n \geq 1$. Then the sequence $\left\{x_{n}\right\}$ converges strongly to a fixed point of $T$. 
REMARK 19. Corollaries 17 and 18 extend and improve Theorems 2 and 3 of Liu [12] by weakening the asymptotic regular on $T$ and removing some redundant restrictions on the iterative parameters $\left\{\alpha_{n}\right\}$ and $\left\{\beta_{n}\right\}$.

Let $(X, d)$ be a metric space and $I=[0,1]$. A continuous mapping $W: X \times X \times I \rightarrow X$ is called a convex structure on $X$ if, for all $(x, y, \alpha) \in X \times X \times I$ and $u \in X$,

$$
d(u, W(x, y, \alpha)) \leq \alpha d(u, x)+(1-\alpha) d(u, y)
$$

A metric space $(X, d)$ together with a convex structure $W$ is called a convex metric space. A nonempty subset $C$ of a convex metric space $(X, d)$ is said to be convex if $W(x, y, \alpha) \in C$ for all $x, y \in C$ and $\alpha \in I$. Obviously, all normed linear spaces and their convex subsets are convex metric spaces, but there are many examples of convex metric spaces which are not embedded in any normed linear spaces (see [22]).

In [22], Takahashi introduced initially the notion of convex metric spaces and studied fixed point theory for nonexpansive mappings in convex metric spaces. Also, Naimpally et al. [15], Rhoades et al. [18], and many others have proved fixed point theorems in convex metric spaces. Furthermore, Goebel and Kirk [8] and Kirk [11] used convex metric spaces as hyperbolic type spaces and studied the iterative sequences for nonexpansive mappings in hyperbolic type spaces, and Ding [5] dealt with the Ishikawa iterative sequence to construct fixed points of quasicontractive, generalized quasicontractive, and quasi-nonexpansive mappings in convex metric spaces.

Inspired and motivated by the notion of the convex structure, we introduce the following definition for our main theorems in this paper.

DeFINITION 20. Let $(X, d)$ be a metric space, let $C$ be a nonempty convex subset of $X$, and let $I=[0,1]$. A mapping $W: C \times C \times C \times I \times I \times I \rightarrow C$ is called a convex structure on $C$ if, for all $x, y, z \in C, u \in C$ and $\alpha, \beta, \gamma \in I$ with $\alpha+\beta+\gamma=1$,

$$
d(u, W(x, y, z, \alpha, \beta, \gamma)) \leq \alpha d(u, x)+\beta d(u, y)+\gamma d(u, z) .
$$

Note that every metric space with the convex structure $W$ with $\gamma=0$ given in Definition 20 is a convex metric space in the sense of Takahashi.

In this paper, motivated by Theorems 7, 9, and 10 concerning the convergence conditions of the iterative schemes for quasi-nonexpansive and asymptotically quasi-nonexpansive mappings in Banach spaces, by using Theorem 13, we prove some convergence theorems of the modified Ishikawa iterative sequence with errors for uniformly quasiLipschitzian mappings in metric spaces with the convex structure $W$. Our results generalize and improve Theorems 7, 9, and 10, and many others in several ways.

Now, we prove the main results in this paper.

THEOREM 21. Let $(X, d)$ be a complete metric space with the convex structure $W$ given in Definition 20, let $C$ be a nonempty convex closed subset of $X$ and let $T: C \rightarrow C$ be a uniformly quasi-Lipschitzian mapping with the Lipschitz constant $L \geq 1$. For an arbitrary 
initial value $x_{0} \in C$, let $\left\{x_{n}\right\}$ be a sequence in $C$ defined by

$$
\begin{aligned}
& y_{n}=W\left(x_{n}, T^{n} x_{n}, v_{n}, \bar{a}_{n}, \bar{b}_{n}, \bar{c}_{n}\right), \quad n \geq 0, \\
& x_{n+1}=W\left(x_{n}, T^{n} y_{n}, u_{n}, a_{n}, b_{n}, c_{n}\right), \quad n \geq 0 \text {, }
\end{aligned}
$$

where $\left\{u_{n}\right\},\left\{v_{n}\right\}$ are bounded sequences in $C$ and $\left\{a_{n}\right\},\left\{b_{n}\right\},\left\{c_{n}\right\},\left\{\bar{a}_{n}\right\},\left\{\bar{b}_{n}\right\},\left\{\bar{c}_{n}\right\}$ are sequences in $[0,1]$ with the restrictions $a_{n}+b_{n}+c_{n}=\bar{a}_{n}+\bar{b}_{n}+\bar{c}_{n}=1, \sum_{n=1}^{\infty} b_{n}<+\infty$, $\sum_{n=1}^{\infty} c_{n}<+\infty$, and $\sum_{n=1}^{\infty} \bar{c}_{n}<+\infty$. Then the sequence $\left\{x_{n}\right\}$ converges strongly to a point $p \in F(T)$ if and only if

$$
\liminf _{n \rightarrow \infty} d\left(x_{n}, F(T)\right)=0 .
$$

Proof. The necessity is obvious and so the proof is omitted. Now, we will prove the sufficiency. For any $p \in F(T)$, set

$$
M=\max \left\{\sup _{n \geq 1}\left\{d\left(u_{n}, p\right)\right\}, \sup _{n \geq 1}\left\{d\left(v_{n}, p\right)\right\}\right\} .
$$

Since the mapping $T: C \rightarrow C$ is uniformly quasi-Lipschitzian, by using (39), we have

$$
\begin{aligned}
d\left(y_{n}, p\right) & \leq \bar{a}_{n} d\left(x_{n}, p\right)+\bar{b}_{n} d\left(T^{n} x_{n}, p\right)+\bar{c}_{n} d\left(v_{n}, p\right) \\
& \leq\left(\bar{a}_{n}+\bar{b}_{n} L\right) d\left(x_{n}, p\right)+\bar{c}_{n} M \\
& =\left(1-\bar{b}_{n}-\bar{c}_{n}+\bar{b}_{n} L\right) d\left(x_{n}, p\right)+M \bar{c}_{n} \\
& =\left[1+(L-1) \bar{b}_{n}\right] d\left(x_{n}, p\right)+M \bar{c}_{n} \\
& =L d\left(x_{n}, p\right)+M \bar{c}_{n}, \\
d\left(x_{n+1}, p\right) & \leq a_{n} d\left(x_{n}, p\right)+b_{n} d\left(T^{n} y_{n}, p\right)+c_{n} d\left(u_{n}, p\right) \\
& \leq\left(1-b_{n}\right) d\left(x_{n}, p\right)+b_{n} L d\left(y_{n}, p\right)+c_{n} M \\
& \leq\left[1+\left(L^{2}-1\right) b_{n}\right] d\left(x_{n}, p\right)+L M\left(\bar{c}_{n}+c_{n}\right),
\end{aligned}
$$

which shows that the sequence $\left\{x_{n}\right\}$ is of monotone type by our assumptions $\left\{b_{n}\right\}$, $\left\{c_{n}\right\}$, and $\left\{\bar{c}_{n}\right\}$. On the other hand, $F(T)$ is a closed subset of $C$ since $T$ is uniformly quasi-Lipschitzian. Therefore, By Theorem 13, the conclusion follows. This completes the proof.

Corollary 22. Let $(X, d)$ be a complete metric space, let $C$ be a nonempty convex closed subset of $X$, and let $T: C \rightarrow C$ be a uniformly quasi-Lipschitzian mapping with the Lipschitz constant $L \geq 1$. Let $W$ be the convex structure defined by $W(x, y, z, \alpha, \beta, \gamma)=$ $\alpha x+\beta y+\gamma z$ for all $x, y, z \in C$ and $\alpha, \beta, \gamma \in I$ with $\alpha+\beta+\gamma=1$. Let $\left\{x_{n}\right\}$ be a sequence in $C$ defined by (18) for $x_{1} \in C$, where $\left\{u_{n}\right\},\left\{v_{n}\right\}$ are bounded sequences in $C$ and $\left\{a_{n}\right\}$, $\left\{b_{n}\right\},\left\{c_{n}\right\},\left\{\bar{a}_{n}\right\},\left\{\bar{b}_{n}\right\},\left\{\bar{c}_{n}\right\}$ are sequences in $[0,1]$ with $a_{n}+b_{n}+c_{n}=\bar{a}_{n}+\bar{b}_{n}+\bar{c}_{n}=1$, $\sum_{n=1}^{\infty} b_{n}<+\infty, \sum_{n=1}^{\infty} c_{n}<+\infty$, and $\sum_{n=1}^{\infty} \bar{c}_{n}<+\infty$. Then the sequence $\left\{x_{n}\right\}$ converges strongly to a point $p \in F(T)$ if and only if

$$
\liminf _{n \rightarrow \infty} d\left(x_{n}, F(T)\right)=0 .
$$


Proof. The proof follows from Theorem 21.

As immediate consequences of Corollary 22, we have the following corollary.

Corollary 23. Let $X$ be a Banach space, let $C$ be a nonempty convex closed subset of $X$, and let $T: C \rightarrow C$ be a uniformly quasi-Lipschitzian mapping. Let $\left\{x_{n}\right\}$ be the same sequence as in Corollary 22. Then the sequence $\left\{x_{n}\right\}$ converges strongly to a point $p \in F(T)$ if and only if

$$
\liminf _{n \rightarrow \infty} d\left(x_{n}, F(T)\right)=0
$$

Proof. The conclusion follows from Corollary 22 with the metric $d(x, y)=\|x-y\|$ and the convex structure $W$ defined by $W(x, y, z, \alpha, \beta, \gamma)=\alpha x+\beta y+\gamma z$ for all $x, y, z \in$ $C$ and $\alpha, \beta, \gamma \in I$ with $\alpha+\beta+\gamma=1$.

Corollary 24. Let $X$ be a Banach space, let $C$ be a nonempty convex closed subset of $X$, and let $T: C \rightarrow C$ be an asymptotically quasi-nonexpansive mapping. Let $\left\{x_{n}\right\}$ be the same sequence as in Corollary 22. Then the sequence $\left\{x_{n}\right\}$ converges strongly to a point $p \in F(T)$ if and only if

$$
\liminf _{n \rightarrow \infty} d\left(x_{n}, F(T)\right)=0 .
$$

Proof. Since $T: C \rightarrow C$ is asymptotically quasi-nonexpansive, we have

$$
\left\|T^{n}-p\right\| \leq\left(1+k_{n}\right)\|x-p\|
$$

for all $x \in C, p \in F(T)$, and $n \geq 1$, where $k_{n} \geq 0$ and $k_{n} \rightarrow 0$ as $n \rightarrow \infty$. Setting $L=$ $1+\sup \left\{k_{n}: n \geq 1\right\}$, then we have

$$
\left\|T^{n} x-p\right\| \leq L\|x-p\|
$$

for all $x \in C, p \in F(T)$, and $n \geq 1$, which shows that $T$ is uniformly quasi-Lipschitzian. Therefore, Corollary 24 follows from Corollary 23. This completes the proof.

REMARK 25. Theorem 21 gives an actual example for our early general convergence principle (see, [27, Theorem 2.1]). Corollaries 22, 23, and 24 generalize and improve Theorems 7, 9, and 10, and many others.

THEOREM 26. Let $X$ be a Banach space, let $C$ be a nonempty convex closed subset of $X$, and $\left\{x_{n}\right\}$ be a sequence in $C$ defined by (18) for $x_{1} \in C$, where $\left\{u_{n}\right\},\left\{v_{n}\right\}$ are bounded sequences in $C$ and $\left\{a_{n}\right\},\left\{b_{n}\right\},\left\{c_{n}\right\},\left\{\bar{a}_{n}\right\},\left\{\bar{b}_{n}\right\},\left\{\bar{c}_{n}\right\}$ are sequences in $[0,1]$ with $a_{n}+$ $b_{n}+c_{n}=\bar{a}_{n}+\bar{b}_{n}+\bar{c}_{n}=1$. Let $T: C \rightarrow C$ be an asymptotically quasi-nonexpansive mapping with $F(T) \neq \varnothing$ and a sequence $\left\{k_{n}\right\}$ in $[0, \infty)$ satisfying $\sum_{n=1}^{\infty} b_{n}\left(k_{n}^{2}-1\right)<+\infty$. If

$$
\liminf _{n \rightarrow \infty} d\left(x_{n}, F(T)\right)=0 \text {, }
$$

then the sequence $\left\{x_{n}\right\}$ converges strongly to a point $p \in F(T)$. 
Proof. For any $p \in F(T)$, set

$$
M=\max \left\{\sup _{n \geq 1}\left\{\left\|u_{n}-p\right\|\right\}, \sup _{n \geq 1}\left\{\left\|v_{n}-p\right\|\right\}\right\} .
$$

Then, by using (18), we have

$$
\begin{aligned}
\left\|y_{n}-p\right\| & \leq \bar{a}_{n}\left\|x_{n}-p\right\|+\bar{b}_{n} k_{n}\left\|x_{n}-p\right\|+\bar{c}_{n}\left\|v_{n}-p\right\| \\
& \leq\left(1-\bar{b}_{n}+\bar{b}_{n} k_{n}\right)\left\|x_{n}-p\right\|+\bar{c}_{n} M \\
& =\left[1+\bar{b}_{n}\left(k_{n}-1\right)\right]\left\|x_{n}-p\right\|+M \bar{c}_{n} \\
& \leq k_{n}\left\|x_{n}-p\right\|+M \bar{c}_{n},
\end{aligned}
$$

and so

$$
\begin{aligned}
\left\|x_{n+1}-p\right\| & \leq a_{n}\left\|x_{n}-p\right\|+b_{n} k_{n}\left\|y_{n}-p\right\|+c_{n}\left\|u_{n}-p\right\| \\
& \leq\left(1-b_{n}+b_{n} k_{n}^{2}\right)\left\|x_{n}-p\right\|+\bar{c}_{n} b_{n} k_{n} M+c_{n} M \\
& \leq\left[1+b_{n}\left(k_{n}^{2}-1\right)\right]\left\|x_{n}-p\right\|+\left(\bar{c}_{n}+c_{n}\right) M .
\end{aligned}
$$

Therefore, by our assumptions, we know that the sequence $\left\{x_{n}\right\}$ is of monotone type and so the conclusion follows from Theorem 13. This completes the proof.

REMARK 27. Theorem 26 improves [3, Theorem 3.2] in several ways.

COROLLARY 28. Let $C$ be a closed convex subset of a complete convex metric space $X$ with the convex structure $W$ in the sense of Takahashi and let $T: C \rightarrow C$ be a uniformly quasi-Lipschitzian mapping. Suppose that, for an arbitrary initial value $x_{0} \in C$, the iterative sequence $\left\{x_{n}\right\}$ is defined by

$$
\begin{aligned}
& x_{n+1}=W\left(T^{n} y_{n}, x_{n}, \alpha_{n}\right), \quad n \geq 0, \\
& y_{n}=W\left(T^{n} x_{n}, x_{n}, \beta_{n}\right), \quad n \geq 0 \text {, }
\end{aligned}
$$

where $\left\{\alpha_{n}\right\}$ and $\left\{\beta_{n}\right\}$ are sequences in $(0,1)$ satisfying $\sum_{n=1}^{\infty} \alpha_{n}<+\infty$. Then the sequence $\left\{x_{n}\right\}$ converges strongly to a point $p \in F(T)$ if and only if $\liminf _{n \rightarrow \infty} d\left(x_{n}, F(T)\right)$ $=0$.

Proof. The proof follows from Theorem 21 with $b_{n}=\alpha_{n}, \bar{b}_{n}=\beta_{n}, c_{n}=\bar{c}_{n}=0$, and $u_{n}=v_{n}=0$ for all $n \geq 0$.

REMARK 29. If $L=1$, then the condition $\sum_{n=1}^{\infty} \alpha_{n}<+\infty$ in Corollary 28 can be removed.

From Corollary 28, we have the following corollary.

Corollary 30. Let $X$ be a Banach space, let $C$ be a nonempty convex closed subset of $X$, and let $T: C \rightarrow C$ be a uniformly quasi-Lipschitzian mapping. Let $\left\{x_{n}\right\}$ be the sequence defined by (14) for $x_{1} \in C$, where $\left\{\alpha_{n}\right\}$ and $\left\{\beta_{n}\right\}$ are sequences in $[0,1]$ satisfying $\sum_{n=1}^{\infty} \alpha_{n}<+\infty$. Then the sequence $\left\{x_{n}\right\}$ converges strongly to a point $p \in F(T)$ if and only if $\liminf _{n \rightarrow \infty} d\left(x_{n}, F(T)\right)=0$. 
Proof. Define a metric function $d(x, y)=\|x-y\|$ for all $x, y \in C$ and a convex structure $W$ by

$$
W(x, y, \alpha)=\alpha x+(1-\alpha) y
$$

for all $x, y \in C$ and $\alpha \in I$. Then $(X, d)$ is a complete metric space with the convex structure $W$. Therefore, by Corollary 28, we have the conclusion of Corollary 30. This completes the proof.

Corollary 31. Let $X$ be a Banach space, let $C$ be a nonempty convex closed subset of $X$, and let $T: C \rightarrow C$ be an asymptotically quasi-nonexpansive mapping. Let $\left\{x_{n}\right\}$ be the same sequence as in Corollary 30. Then the sequence $\left\{x_{n}\right\}$ converges strongly to a point $p \in F(T)$ if and only if $\liminf _{n \rightarrow \infty} d\left(x_{n}, F(T)\right)=0$.

Proof. Every asymptotically quasi-nonexpansive mapping is uniformly quasi-Lipschitzian and so, from Corollary 30, the conclusion follows.

ACKNOWLEDGMENT. The third and fourth authors were supported by the Korea Research Foundation Grant KRF-2003-002-C00018.

\section{REFERENCES}

[1] S.-S. Chang, Y. J. Cho, and H. Y. Zhou, Iterative Methods for Nonlinear Operator Equations in Banach Spaces, Nova Science Publishers, New York, 2002.

[2] C. E. Chidume, Convergence theorems for asymptotically pseudocontractive mappings, Nonlinear Anal. 49 (2002), no. 1, 1-11.

[3] Y. J. Cho, H. Y. Zhou, H. G. Hyun, and J. K. Kim, Convergence theorems of iterative sequences for asymptotically nonexpansive mappings in Banach spaces, Panamer. Math. J. 13 (2003), no. 1, 77-89.

[4] Y. J. Cho, H. Y. Zhou, S. M. Kang, and S. S. Kim, Approximations for fixed points of $\phi$ hemicontractive mappings by the Ishikawa iterative process with mixed errors, Math. Comput. Modelling 34 (2001), no. 1-2, 9-18.

[5] X. P. Ding, Iteration processes for nonlinear mappings in convex metric spaces, J. Math. Anal. Appl. 132 (1988), no. 1, 114-122.

[6] M. K. Ghosh and L. Debnath, Convergence of Ishikawa iterates of quasi-nonexpansive mappings, J. Math. Anal. Appl. 207 (1997), no. 1, 96-103.

[7] K. Goebel and W. A. Kirk, A fixed point theorem for asymptotically nonexpansive mappings, Proc. Amer. Math. Soc. 35 (1972), 171-174.

[8] - Iteration processes for nonexpansive mappings, Topological Methods in Nonlinear Functional Analysis (Toronto, Ont., 1982) (S. P. Singh, S. Thomeier, and B. Watson, eds.), Contemp. Math., vol. 21, American Mathematical Society, Rhode Island, 1983, pp. 115-123.

[9] J. Górnicki, Weak convergence theorems for asymptotically nonexpansive mappings in uniformly convex Banach spaces, Comment. Math. Univ. Carolin. 30 (1989), no. 2, 249252.

[10] W. A. Kirk, Fixed point theorems for non-Lipschitzian mappings of asymptotically nonexpansive type, Israel J. Math. 17 (1974), 339-346.

[11]__ Krasnosel'skii's iteration process in hyperbolic space, Numer. Funct. Anal. Optim. 4 (1982), no. 4, 371-381.

[12] Q. Liu, Iterative sequences for asymptotically quasi-nonexpansive mappings, J. Math. Anal. Appl. 259 (2001), no. 1, 1-7. 
[13] _ Iterative sequences for asymptotically quasi-nonexpansive mappings with error member, J. Math. Anal. Appl. 259 (2001), no. 1, 18-24.

[14] Q. Liu and L.-X. Xue, Convergence theorems of iterative sequences for asymptotically nonexpansive mapping in a uniformly convex Banach space, J. Math. Res. Exposition 20 (2000), no. 3, 331-336.

[15] S. A. Naimpally, K. L. Singh, and J. H. M. Whitfield, Fixed points in convex metric spaces, Math. Japon. 29 (1984), no. 4, 585-597.

[16] M. O. Osilike and D. I. Igbokwe, Weak and strong convergence theorems for fixed points of pseudocontractions and solutions of monotone type operator equations, Comput. Math. Appl. 40 (2000), no. 4-5, 559-567.

[17] W. V. Petryshyn and T. E. Williamson Jr., Strong and weak convergence of the sequence of successive approximations for quasi-nonexpansive mappings, J. Math. Anal. Appl. 43 (1973), 459-497.

[18] B. E. Rhoades, K. L. Singh, and J. H. M. Whitfield, Fixed points for generalized nonexpansive mappings, Comment. Math. Univ. Carolin. 23 (1982), no. 3, 443-451.

[19] J. Schu, Iterative construction of fixed points of asymptotically nonexpansive mappings, J. Math. Anal. Appl. 158 (1991), no. 2, 407-413.

[20] - Weak and strong convergence to fixed points of asymptotically nonexpansive mappings, Bull. Austral. Math. Soc. 43 (1991), no. 1, 153-159.

[21] H. F. Senter and W. G. Dotson Jr., Approximating fixed points of nonexpansive mappings, Proc. Amer. Math. Soc. 44 (1974), 375-380.

[22] W. Takahashi, A convexity in metric space and nonexpansive mappings. I, Kōdai Math. Sem. Rep. 22 (1970), 142-149.

[23] K.-K. Tan and H. K. Xu, Approximating fixed points of nonexpansive mappings by the Ishikawa iteration process, J. Math. Anal. Appl. 178 (1993), no. 2, 301-308.

[24] _ Fixed point iteration processes for asymptotically nonexpansive mappings, Proc. Amer. Math. Soc. 122 (1994), no. 3, 733-739.

[25] H. K. Xu, Existence and convergence for fixed points of mappings of asymptotically nonexpansive type, Nonlinear Anal. 16 (1991), no. 12, 1139-1146.

[26] Y. Xu, Ishikawa and Mann iterative processes with errors for nonlinear strongly accretive operator equations, J. Math. Anal. Appl. 224 (1998), no. 1, 91-101.

[27] H. Y. Zhou, G. L. Gao, G. T. Guo, and Y. J. Cho, Some general convergence principles with applications, Bull. Korean Math. Soc. 40 (2003), no. 3, 351-363.

[28] H. Y. Zhou and Y. Jia, Approximating the zeros of accretive operators by the Ishikawa iteration process, Abstr. Appl. Anal. 1 (1996), no. 2, 153-167.

Haiyun Zhou: Department of Mathematics, Shijiazhuang Mechanical Engineering College, Shijiazhuang 050003, China

E-mail address: wi tman66@yahoo.com.cn

Jung Im Kang: Department of Mathematics, Research Institute of Natural Sciences, College of Natural Sciences, Gyeongsang National University, Chinju 660-701, Korea

E-mail address: jungim-kang@hanmai 1 . net

Shin Min Kang: Department of Mathematics, Research Institute of Natural Sciences, College of Natural Sciences, Gyeongsang National University, Chinju 660-701, Korea

E-mail address: smkang@nongae.gsnu.ac.kr

Yeol Je Cho: Department of Mathematics, Education Research Institute of Natural Sciences, College of Education, Gyeongsang National University, Chinju 660-701, Korea

E-mail address: yjcho@nongae.gsnu.ac.kr 


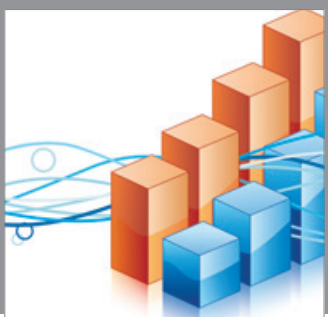

Advances in

Operations Research

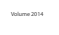

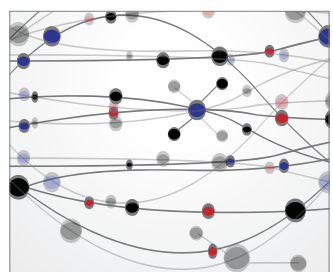

\section{The Scientific} World Journal
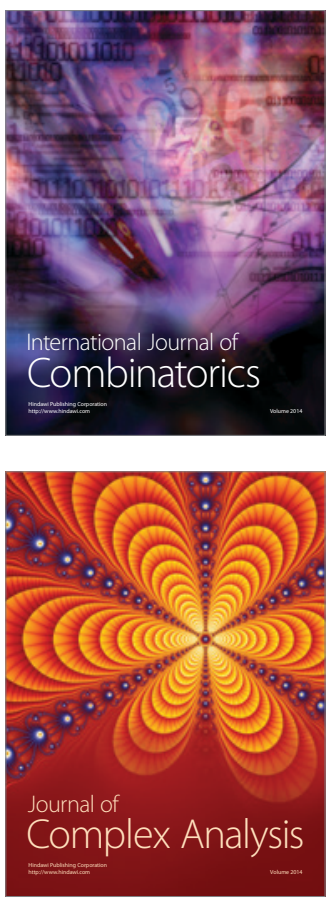

International Journal of

Mathematics and

Mathematical

Sciences
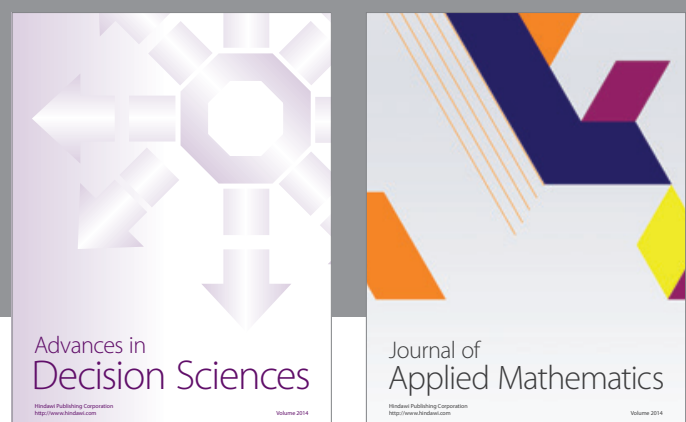

Journal of

Applied Mathematics
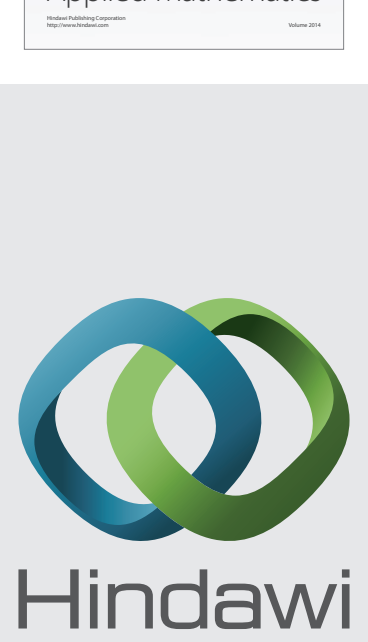

Submit your manuscripts at http://www.hindawi.com
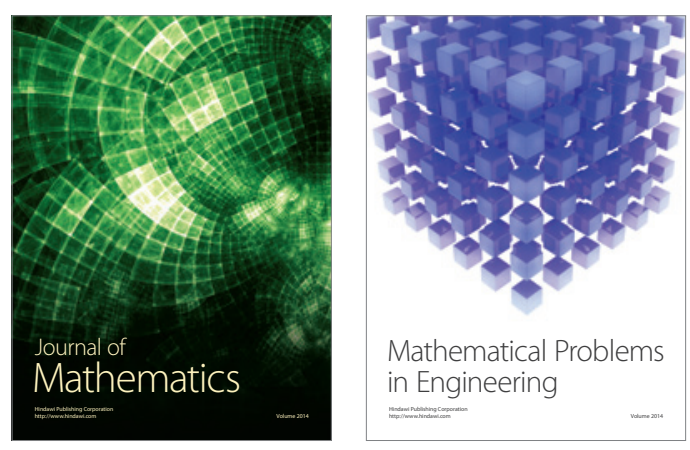

Mathematical Problems in Engineering
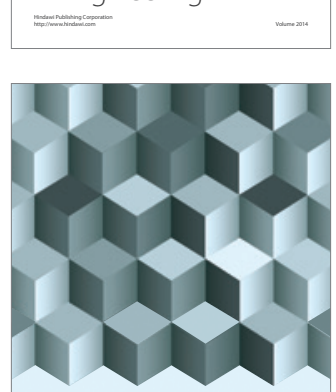

Journal of

Function Spaces
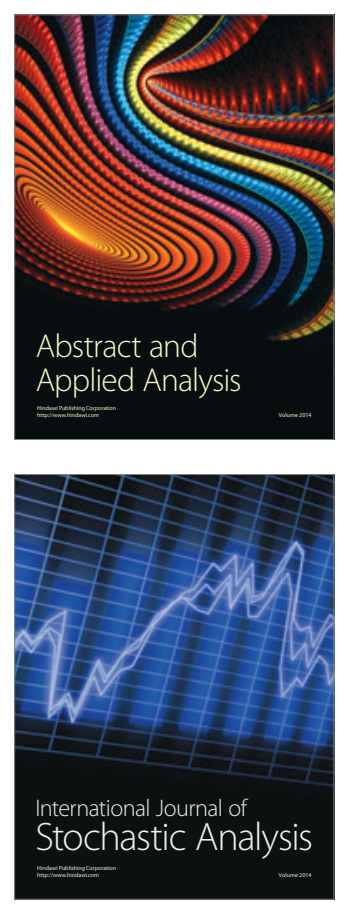

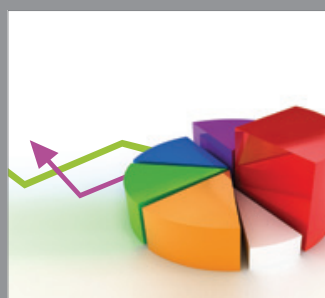

ournal of

Probability and Statistics

Promensencen
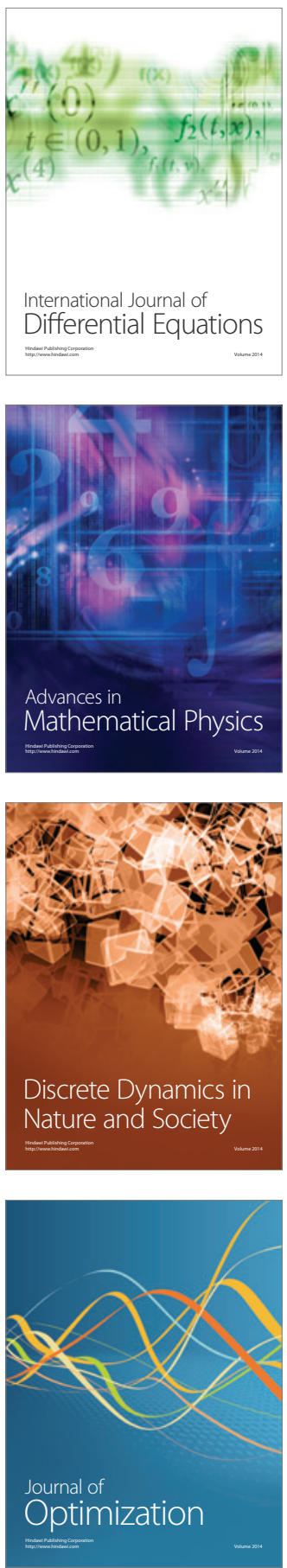